\title{
Species Test of Morus alba, Morus cathayana and Morus nigra on Agroforestry Land as Silkworm Feed (Bombyx mory Linn.) For Silk Yarn Quality Improvement in Bali Indonesia
}

\author{
Nanang Sasmita \\ Faculty of Agriculture, Udayana University \\ Jl. PB Sudirman Denpasar Bali, Indonesia
}

\begin{abstract}
Mulberry plants are tested on agroforestry land because of its well adaptation. The agroforestry model is a combination of sengon (Paraserianthe sfalcataria) and mulberry (Morus sp.) plants. The selected mulberry plants consisted of three species, namely $M$. alba, M. cathayana and $M$. nigra. The study objectives was to determine the best mulberry species leaves as silkworm feed to produce quality cocoons on agroforestry area in Bali. The test was carried out in a complete randomized design (CRD) with the species treatment of $M$. alba, M. cathayana and M. nigra. It consists of three replications each. Each replication consists of 100 silkworms. The variables observed in this study were cocoon quality and thread / fiber including the percentage of larvae which become a cocoon, the percentage of normal cocoon, cocoon weight, cocoon skin weight, ratio of cocoon skin and fiber length. The results showed that the maintenance rendement (\%) was M. alba (70\%), M. cathayana $(62,0)$ and $M$. nigra $(60,5)$, weight of cocoon $(\mathrm{g})$, was M. alba $(1,47)$, M. cathayana $(1.53)$ and M. nigra (1.41), Weight of filaments (mg)namely M. alba $(30,12)$, M. cathayana $(25,35)$ and M. nigra $(26,25)$, and the rolling strength of silk thread, namely M. alba (97.45), M. cathayana (74.11) and M. nigra (69.27). M. alba, M. nigra and M. cathayana mulberry leaf species grown from agroforestry patterns can be used to feed silkworms. The mulberry cropping pattern type both monoculture and agroforestry did not show a significant difference in the silkworm cocoons quality and quantity. The highest maintenance rendement is silkworm fed by $M$. alba, second is $M$. cathayana and third M. nigra. M. nigra and M. cathayana compared to M. alba did not show significant differences in cocoon weight, cocoon skin weight, percentage of filaments and rolling strength of silk yarn.
\end{abstract}

Keywords: Agroforestry, cocoon, mulberry, silkworm, feed

\section{Introduction}

The forestry regulation of the Republic of Indonesia Minister in 2007 states that non-timber forest products are forest products along with other products, except wood as material that is used for economic activities and improving people's welfare. The government has set criteria and indicators for determining the national flagship types that are prioritized in its development, namely natural silk, honey (natural honey), aloes and bamboo. The volume of exports and imports of natural silk commodities in the form of cocoon, silk yarn and silk fabrics fluctuated from year to year. The natural silk imports volume in 2012 was smaller but the volume of natural silk exports was 95.000 tons. In 2013 the imports volume of natural silk declined. The natural silk exports volume has increased, previously in 2012 it exported 95.000 tons, but in 2013 it increased to 141.654 tons. The import volume decline and export volume increase is an opportunity for Indonesia's natural silk to be developed again, because Indonesia's ability to meet national demand is quite well marked by declining of imports volume and the export volumes increasing. This shows that the natural silk commodity can be one of the leading commodities for Indonesia.

Mulberry (Morus sp.) is a broadleaf wood plant. Mulberry plants have been cultivated for silkworms maintenance. The the determinants of mulberry plants quality and quantity is one of silkworm maintenance the continuity. Availability of quality plants is strongly influenced by mulberry cultivation systems. The selection of planted varieties, pruned, fertilized, the pests and diseases attacks and drought in the dry season need to be considered. Most areas of mulberry plant development in Bali are in areas with wet climates. The main centers of natural silk in Bali are located in Bangli Regency. The availability of water in the dry season has a significant effect on the growth and loss of mulberry leaves. The mulberry species that are developed in general are quite maximal because of the optimal growth requirements. According to Santoso and Prayudyaningsih (2005) the loss level of mulberry leaves is influenced by the local climate, wet climate areas have a fairly low loss rate of around $5 \%$ while the dry climate regions reach $13 \%$ to $48.41 \%$.

Mulberry cultivation is generally done by monoculture. In this study mulberry plants were tested on agroforestry area. Agroforestry is an activity that's supporting sustainable forestry and agricultural activities. Mulberry plants are tested on agroforestry area because of its well adaptation. The shape of the agroforestry model studied was a combination of sengon (Paraserianthes falcataria) and mulberry (Morus sp.) Plants. Mulberry plant breeding consists of three speceis, namely M. alba, M. cathayana and M. nigra show high vigority, but still need further research $M$. nigra is a mulberry species which is resistant to drought conditions but 
the size of leaves is small, whereas $M$. cathayana is a mulberry species which has a high leaf production.

In supporting natural silk beside productivity, the high silkworm cocoons productivity is also needed. The silkworms growth and development is influenced by the mulberry quality and quantity as feed (Murthy et al., 2013). A high quality cocoons for silk raw material are obtained from mulberry leaves quality as silkworms feed. For this reason, the research on various mulberry plants species as silkworm feed to produce quality cocoons on agroforestry land in Bali were done.

\section{Materials and Methods}

\subsection{Materials}

The study of the Effect of mulberry leaves on cocoon productivity and quality was carried out from August to September 2018. The study site was in Kintamani, Bangli Regency. With an elevation of $1000 \mathrm{~m}$ above sea level and the average temperature conditions range from $20^{\circ}-2^{\circ} \mathrm{C}$, with of $80 \%-90 \%$ humidity. Mulberry leaves are used as silkworm feed from $M$. alba, M. cathayana and M. nigra which show high vigority (hybrid vigor). Silkworm seeds used from PPUS Candiroto, Central Java Province. Before the maintenance of silkworms, disinfection of the silkworm maintenance room using formalin was carried out, while the disinfection of the silkworm's body used lime mixed with chlorine. The silkworm process to become a cocoon uses paraffin paper. The cementing of silkworms uses a seriframe tool. Furthermore, the resulting cocoon was selected and observed its quality with cocoon quality testing equipment and the data obtained was recorded with writing instruments.

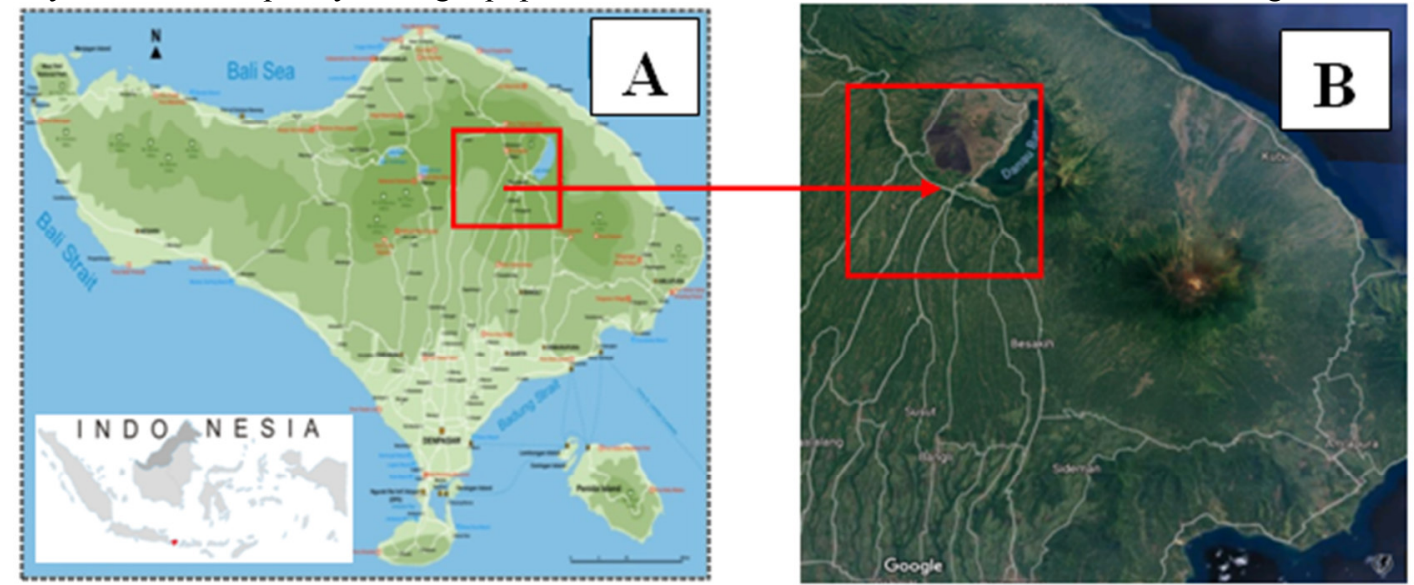

Figure 1.

A. Research Sites in Bali Province, Indonesia.

B. The Centre of Agroforestry Kintamani at $8^{\circ} 26^{\prime} 80.10^{\prime \prime S L}$ and $115^{\circ} 33^{\prime} 54.14$ 'EL

\subsection{Research design}

The test was carried out in a completely randomized design (CRD) with the the species treatment of $M$. alba, $M$. cathayana and M. nigra. Consists of three replications each. Each replication consists of 100 silkworms. The variables observed in this study were the quality of cocoon and thread / fiber including: become a cocoon larvae percentage, normal cocoon percentage, cocoon weight, cocoon skin weight, cocoon skin ratio and fiber length (Muin et al., 2006).

a. The percentage of become a cocoon larvae

The amount of cocoon formed x 100\%

Number of silkworm samples

b. Normal cocoon percentage

The normal cocoons collected are separated from the defective cocoon and are counted in number.

Normal amount of cocoon x 100\%

Overall number of cocoon grains

c. Cocoon weight, cocoon skin weight and cocoon skin ratio

Cocoon weight and cocoon skin weight are calculated by taking a normal cocoon that has been selected, then peeling the cocoon skin as much as 20 cocoons then weighing the cocoon with pupa and cocoon skin. The weight of the cocoon and the weight of the cocoon skin is the average weight of 20 sample cocoon grains in grams. Cocoon skin ratio is calculated using this approach :

Cocoon skin weight X 100\%

Cocoon weight

d. length is calculated by approach

Thread length $\mathrm{x}$ average number of cocoons per thread $\times 100 \%$ 
The amount of cocoon spun

Matters related to the research are as follows :

a. Cocoon quality

Rochmawati (2011) stated that based on Indonesia National Standard (INS) the class of fresh cocoon quality was divided into four classes, they are A, B, C, and D with three test parameters, namely cocoon weight, cocoon skin ratio and percentage of defective cocoon. Besides that, it was also observed the percentage of larvae that become a cocooon because cocoon is the end result of silkworms maintenance. This cocoon will then be processed into silk yarn, so that the quality and quantity will affect the productivity of the business that carried out.

1. The percentage of become a cocoon larvae

The percentage of become a cocoon larvae is the ratio between the number of larvae that become a cocoon with the number of sample larvae. This is supported by the study results of Kumar et al., (2013) that differences in mulberry species and maintenance season can affect the growth and nature of silkworm cocoons.

2. Normal cocoon

Normal cocoon is a cocoon that is in good condition (normal shape, not thin and not deformed) so that it can be spun into silk thread. The higher the percentage of the normal cocoon, the lower the number of defective cocoons and the more cocoons that can be spun so that the yarn produced will also increase.

3. Cocoon weight, Cocoon skin weight and Percentage of cocoon skin

Cocoon weight is important in silkworm cultivation because it will affect the fiber and yarn produced. One of the main factors that can affect the quality of the cocoon become better is the quality of the leaves. A mulberry leaves with a good quality are easily digested according to their growth rate and contain all the substances needed for the silkworms growth of (Nursita, 2011). The weight of the cocoon's skin, which is the higher the weight of the skin, the greater the content of the cocoon. This varies, according to silkworm varieties, maintenance conditions and process to become a cocoon (Atmosoedarjo et al., 2000). Cocoon skin ratio, is a comparison between the weight of the cocoon skin and the weight of the whole cocoon.

b. Fiber quality

The silk fibers quality determines in the spinning process because it will affect the silk thread produced. The better the quality of the fiber from the cocoon to be spun, the silk yarn obtained will also increase both the quality and quantity.

\subsection{Data Analysis}

The linear model used is Yst $=\mu+$ As $+E s$, where Yst $=$ observation value, $\mu=$ general mean, As $=$ Mulberry species affect and $\varepsilon_{\text {st }}=$ eror random affect.

Yst $=\mu+\mathrm{Bi}+$ Estq, Information : Yst $=$ observed variable

$\mu=$ middle population value

$\mathrm{Bi}=$ mulberry species to $\mathrm{i}$

Estq $\quad=$ Trial error

The response variable observed was the percentage of small silkworm deaths (instar I - III) was the number of dead silkworms divided by the number of silkworms (instar I - III) x 100\%. The percentage of large silkworms deaths (instar IV - V) is the number of dead silkworms divided by the number of silkworms (IV instar - V) $\times 100 \%$. The percentage of maintenance rendement is the amount of cocoon yield divided by the number of silkwormsmaintained from the initial instar IV $\mathrm{x} 100 \%$. The wet cocoon weight is the weight of the whole cocoon including the cocoon skin and the pupil. Cocoon skin weight is the weight of a wet cocoon that has been removed from the cocoon. Percentage of cocoon skin weight is the weight of the cocoon skin divided by wet cocoon weight $\times 100 \%$. Measuring filament length and rolling strength.

\section{Results and Discussion}

Observations of the three mulberry species $M$. alba, M. cathayana and $M$. nigra, the analysis of variance showed mulberry species had a significant effect on maintenance rendement, but mulberry species had no significant effect on the percentage of small silkworm deaths, percentage of large silkworm deaths, wet cocoon weight weight of cocoon skin, percentage of cocoon skin, filament length, filament weight, filament percentage, rolling strength. The results of the DMRT test for maintenance rendement, weight of filaments and rolling strength are presented in Table 1. 
Tabel 1. Effect of mulberry leaves for silkworm feed on yield and quality of cocoon

\begin{tabular}{lllll}
\hline Species & $\begin{array}{l}\text { Maintenance } \\
\text { Rendement (\%) }\end{array}$ & $\begin{array}{l}\text { Weight of Cocoon } \\
\text { (g/ cocoon) }\end{array}$ & $\begin{array}{l}\text { Filamen Weight } \\
(\mathbf{m g})\end{array}$ & $\begin{array}{l}\text { Rolling Strength } \\
(\mathbf{\%})\end{array}$ \\
\hline M. alba & $70,0 \mathrm{a}$ & $1,47 \mathrm{ab}$ & $30,12 \mathrm{a}$ & $97,45 \mathrm{a}$ \\
M. cathayana & $62,0 \mathrm{~b}$ & $1,53 \mathrm{a}$ & $25,35 \mathrm{~b}$ & $74,11 \mathrm{ab}$ \\
M. nigra & $60,5 \mathrm{c}$ & $1,41 \mathrm{~b}$ & $26,25 \mathrm{~b}$ & $69,27 \mathrm{~b}$ \\
\hline
\end{tabular}

The average value followed by the same letter is not significantly different at the level of $5 \%$ according to the Duncan test

\subsection{Death of Silkworms (\%)}

mulberry leaves Feeding of M. alba, M. cathayana and M. nigra showed that the highest percentage of small silkworms death was silkworms fed with $M$. alba and $M$. cathayana leaves $(2.1 \%)$, while the least were $M$. nigra silkworms fed $(0.9 \%)$. From the statistical test it did not show any real differences. Variance analysis test results were not significantly different, that mean $M$. cathayana and $M$. nigra can be used as small silkworm feed, as $M$. alba which is commonly used by silkworm farmers in the area. The death of large silkworms showed that the highest percentage were silkworms fed with M. cathayana leaves (35.5\%), while the least silkworms were fed $M$. alba $(15.10 \%)$. Analysis of variance does not show a significant difference. The analysis results of nonsignificant variance analysis mean that $M$. cathayana and $M$. nigra can be used as large silkworm feed. The results stated that the use of $M$. alba or M. cathayana and M. nigra gave almost the same percentage of large silkworm deaths. This means that the use of M. alba can be replaced with M. cathayana and M. nigra. According to Reddy (1984) states that the silkworms survival is strongly influenced by environmental factors, especially temperature, humidity, environmental cleanliness during maintenance, beside the environmental factors the feeding must match with the needs and growth of silkworms. Areas with a high pollution contaminated, cause the flour stored in the leaves of plants. Kamilova and Tsarev (2008) stated that flour can damage the development of silkworms and cause high mortality rates. The effect of temperature and humidity on the Bombyx mori life is significant at every $5^{\circ} \mathrm{C}$ temperature differences. Temperatures exceeding $35^{\circ} \mathrm{C}$ cause disturbed metabolic functions, resulting poor silkworm growth, which affects the silk gland growth and the larvae status health. Similarly, when temperatures drop below $20^{\circ} \mathrm{C}$, metabolic functions become inactive again (Sisodia and Gaherwal, 2017).

\subsection{Maintenance Rendement (\%)}

Feeding mulberry leaves of $M$. alba, M. cathayana and M. nigra showed that the highest percentage of maintenance rendement was silkworms fed by $M$. alba $(70.0 \%)$. The lowest maintenance rendement was silkworms fed by $M$. nigra $(60.5 \%)$. Maintenance recovery is an important thing to know because it is very influential on the production produced from each unit of the number of eggs maintained. This study results indicate that the feeding of M. alba is still better than M. cathayana and M. nigra species. Andadari et al (2017) showed that the silkworm maintenance rendement was $90 \%$ on average, which mean silkworms were adaptive to environmental conditions. This shows that the silkworms quality and health are maintained in good condition. In the end it will affect the level of cocoon production produced.

\subsection{Cocoon weight}

The results showed that the heaviest weight of wet cocoon was silkworm fed by $M$. cathayana leaves $(1.53 \mathrm{~g})$. The lightest wet cocoon weight is the silkworm fed on M. nigra leaves $(1.41 \mathrm{~g})$. The results of this study indicate that different feeding provides different cocoon weights. The $M$. cathayana fed can produces the heaviest weight of wet cocoon compared to M. nigra but not significantly with the wet cocoon weight of $M$. alba. Furthermore, the heaviest weight of cocoon skin is silkworm fed on M. nigra leaves $(0.32 \mathrm{~g})$, while the lightest silkworms are fed $M$. cathayana $(0.30 \mathrm{~g})$.Analysis of variance does not show a significant difference. This means that mulberry feeding can be used as silkworm food. Even M. nigra feeds produce heavier cocoon skin weights compared to silkworms fed byM. alba which are commonly used as silkworm feed. The results showed that the heaviest percentage of skin weight of cocoon was silkworm fed M. nigra leaves $(23.45 \%)$, while the lightest was silkworm fed M. cathayana (20.25\%). The results of the analysis of variance did not show significant differences. The use of M. nigra or M. cathayana can be applied instead of M. alba silkworm feed. Even M. nigra produces a better percentage of cocoon skin weight compared to M. alba. If its not the silkworm time to become acocoon yet, it is forced tobecomee cocoon, so the cocoon produced contains little silk thread. The weight percentage of cocoon skin is closely related to the percentage of rawsilk in spinning. The weight percentage of cocoon skin depends on the type of silkworm seedlings (Andadari et al, 1998). Cocoon weight depends on the type of seed, the state of maintenance and process to become a cocoon (Krishnaswami, 1973). Cocoon weight according to Zhang et al (2017) is related to the metabolic rate of silkworms. In these animals there were 523 and 182 enzymes in the respective glands of silk and silkworms, (Dong et al. 2013; Dong et al. 2016) stated that many 
products produced from metabolism detected from silkworms, especially glycosidase, lipase, and proteases. In addition, it has the potential ability to interact with carbohydrates, lipids, and other small molecules. This shows that carbohydrates, fatty acids, and amino acids are important metabolites in silkworms. It should be noted that glycine, alanine, and serine are the main constituents of silk proteins and play an important role in increasing the weight of silkworm cocoons (Mondal et al. 2007).

\subsection{Filament Length and Weight}

Feeding mulberry leaves of M. alba, M. cathayana and M. nigrashowed that the longest filament length was silkworms fed with $M$. alba leaves $(910.35 \mathrm{~m})$, while the shortest ones were silkworms fed by $M$. nigra $(763.24$ $\mathrm{m})$. The analysis of variance results on filament length did not show any significant differences. This means that feeding $M$. nigraor $M$. cathayana can be used as a substitute for $M$. alba even though $M$. alba produces a better filament length than the two species of mulberry. Furthermore, the heaviest weight of the filament is the silkworm fed $M$. alba leaves $(30.12 \mathrm{mg})$, while the lightest filament weight is the silkworm fed M. cathayana $(25.35 \mathrm{mg})$. From the analysis of variants there is a real difference. Feeding silkworms with $M$. alba was significantly different from feeding with $M$. nigraand $M$. cathayana. But feeding silkworms with $M$. nigra leaves did not show differences with silkworms fed with $M$. cathayana leaves. This study results showed that silkworms fed with $M$. alba leaves still showed the greatest filament weight and were significantly different from feeding $M$. nigraor $M$. cathayana. Between the two species of mulberry does not show a real difference. The results showed that the largest percentage of filaments were fed $M$. alba leaves $(20.15 \%)$, while the smallest ones were silkworms fed by $M$. nigra (19.27\%).The results of variance analysis did not show any real differences. The percentage of filaments is determined by the ratio of the weight of the filament and the weight of the cocoon. In this study the percentage of filaments ranged from $19.27 \%$ to $20.15 \%$. So it can be said that the feeding of $M$. nigra and $M$. cathayana is relatively the same in terms of producing the percentage of filaments compared to $M$. alba.The length and weight of the filament is closely related to the smooth operation of the spinning (reelability). Changes often occur related to the size, weight and length of the silk filament. According to Nagaraju and Kumar (1995) that silkworm populations breed throughout the year. Superior seed selection was carried out for the effect of short filament lengths produced over 11 generations, producing two groups with each filament length averaging $876 \mathrm{~m}$ and $704 \mathrm{~m}$. Feeding mulberry leaves is very important, but Bombyxmori silkworms often experience aggressive insect attacks (Rajitha and Savithri, 2015). Therefore, silkworm disease causes a drastic and qualitative reduction in the yield of cocoon.

\subsection{Rolling Strength}

Feeding mulberry leaves of $M$. alba, M. cathayana and $M$. nigra showed that the largest rolling strength was silkworms fed with $M$. alba leaves (97.45), while the smallest ones were silkworms fed by M. nigra (69,27). The results of variance analysis showed that there was a significant difference between $M$. alba feeding and $M$. nigra, but $M$. cathayana feeding was not significantly different from $M$. alba leaf feeding. These results can be said that $M$. alba shows good rolling strength because $M$. alba has a rolling strength of $97.45 \%$. Rolling strength can be said to be good if the rolling strength is greater or equal to $90.0 \%$ according to Choe (1976). Rolling strength test results of $M$. nigra $69.27 \%$ and $M$. cathayana $74.11 \%$ were still less than $90 \%$ because of that the rolling strength of the species was not good. The maintained silkworm determines the significant increase in cocoon weight, filament weight and filament length and rolling strength which shows a positive effect of additional nutrition on mulberry leaves during larval development (Gwalia, 2018). The effect of methoprene (Magadum et al. 1990) on Bombyx mori resulted in a significant increase in larval weight, cocoon weight, filament and silk fiber rolling strength. The study results of Kasmudjo et al. (2007) showed that the species mulberry leaves was of rolling strength and the quality of silk yarn. Mulberry leaves usually have a direct effect on the quality of the cocoon produced, while the quality of fiber is influenced by the quality of spun cocoons (Kumar et al., 2014). The length of fiber investigated by Muin et al (2015) states that the fiber produced has an average value below $900 \mathrm{~m}$ (not good), so it is expected that in subsequent trials the effectiveness of mulberry plants will look more real.

\section{Conclusion}

Mulberry leaf of $M$. alba, M. nigra and M. cathayana species as a result of agroforestry pattern can be used as for feed silk worms. The cropping patterns type both monoculture and agroforestry patterns did not show significant differences in the quality and quantity of silkworm cocoons. The highest maintenance rendement is silkworm fed by $M$. alba, second is $M$. cathayana and third M. nigra. The mulberry speceis of $M$. nigra and $M$. cathayana compared to $M$. alba did not show any difference to the weight of the cocoon, the weight of the cocoon skin, filaments and rolling strength. 


\section{References}

Andadari L, Minarningsih, Rosita Dewi. 2017. Effect of Mulberry species on the Two Hybrid Silkworm Productivity of Bombyx Mori Cocoon. Widyariset Journal. Vol. 3 No. 2. P. 119 - 130.

Andadari from L, Heriyadi E, Suhandi E. 1998.The effect of feeding Mulberry species on the yields and Quality of Bombyxmori L Cocoon. Forest Research Bulletin (Indonesia).

Choe, B.H. 1976. Silk Fiber in Sericulture Technology Part III Seoul National University Press. Korea.

Dong, Z., P. Zhao, C. Wang, Y. Zhang, J. Chen, X. Wang, Y. Lin, and Q. Xia. 2013. Comparative proteomics reveal diverse functions and dynamic changes of bombyx mori silk proteins spun from different development stages. J. Proteome Res 12: 5213-5222.

Dong, Z., Q. Song, Y. Zhang, S. Chen, X. Zhang, P. Zhao, and Q. Xia. 2016. Structure, evolution, and expression of antimicrobial silk proteins, seroins in lepidoptera. Insect Biochem. Mol. Biol. 75: 24-31.

Gwalia A. 2018. Effect of Spirulina, Zink and Their Mixture on The Coccon Characteristics of Silkworm, Bombyx mori L. Book of Indira Gandhi National Open University.

Kamilova E, B Tsarev. 2008. Mortality of silkworms due to air pollution: environmental indicators induced by ecological stress. WIT Transactions on Ecology and the Environment, Vol 110. P. 241-250.

Khonifah. 1990. Effect of Mulberry Leaf Types on Productivity and Quality of Silk Yarn. Faculty of Forestry, GadjahMada University. Yogyakarta.

Krishnaswami, S. 1973. Manual on Sericulture. Silkworm Rearing. Agricultural Service Division. Food and Agriculture Organization of The United Nations. Rome.

Kumar V., Kumar D., and Ram P. 2014. Varietal influence of mulberry on silkworm, Bombyx mori L. growth and development. Research Article. International Journal of Advanced Research, 2(3), 921-927.

Magadum S. B, M. A. Hooli, V. B. Magdum. 1990. Effect of Methoprene on Larval and Cocoon Weight, Ovariole Length, Egg Number and Fecundity of Bombyx mori L. Journal of Entomologia, Vol 8. P 37-40.

Muin, N, Heri Suryanto dan Minarningsih. 2015. Test of Morus khunpai and M.indica Hybrid towards Silkworm Feed. Wallacea Forestry research journal. Vol.4. Issue 2. p. 137-145.

Mondal, M, K. Trivedy, and S. N. Kumar. 2007. The silk proteins, sericin and fibroin in silkworm, Bombyx mori Linn. - a review. Caspian J. Env. Sci. 5: 63-76.

Pudjiono S, Mohammad Naiem. 2007. The Effect of Feeding of Mulberry Hybrid on the Productivity and the Quality of Cocoon of Silkworm. Forest Breeding Jornal. The Centre of Research Bioteknology and breeding of forestry plant. Vol. 1 no. 2.

Rajitha K, G Savithri. 2015. Studies on symptomological and economic parameters of silk cocoons of Bombyx mori inoculated with Beauveria Bassiana (Bals.) Vuill. International Journal of Current Microbiology and Applied Sciences. Volume 4 Number 2. pp. 44-54.

Reddy, G.R. 1984. Genetic and Breeding of Sericulture, Bombyx mori L. Lectures on Sericulture Suramya Publisher, Bengalore.

Samsijah and Andadari L. 1992. Technical Guide of Silkworm culture (Bombyx mori L.) Technical Information no.25. The Centre of Forest and Nature Conservation Research. Bogor.

Santoso, B and Budisantoso, H. 1999. Adaptation of Crossing Yield Mulberry Variety. Proceding Ekspose of Forestry research and development results. Ujung Pandang. 8 February 1999.

Sisodia NS, Santosh Gaherwal. 2017. Effects of temperature and relative humidity on commercial product of silkworm (Bombyx Mori. L). International Journal of Zoology. Volume 2; Issue 5. Page No. 52-55.

Sulthoni, A. 1981.Aspects of Natural Biology in Order to Build and Develop Multipurpose Forest Functions.Proceedings of the Multipurpose Forest Development and Development Workshop. Yogyakarta.

Zhang Y, Dongchao Zhao, Zhu Meng, Zhaoming Dong, Ying Lin, Shiyi Chen, Qingyou Xia, Ping Zhao1. 2017. Wild Silkworm Cocoon Contains More Metabolites Than Domestic Silkworm Cocoon to Improve Its Protection. Journal of Insect Science. Vol 17(5): 105; 1-6. 